\title{
Science blogs and public engagement with science: practices, challenges, and opportunities
}

\author{
Inna Kouper
}

\begin{abstract}
Digital information and communication technologies (ICTs) are novelty tools that can be used to facilitate broader involvement of citizens in the discussions about science. The same tools can be used to reinforce the traditional top-down model of science communication. Empirical investigations of particular technologies can help to understand how these tools are used in the dissemination of information and knowledge as well as stimulate a dialog about better models and practices of science communication.

This study focuses on one of the ICTs that have already been adopted in science communication, on science blogging. The findings from the analysis of eleven blogs are presented in an attempt to understand current practices of science blogging and to provide insight into the role of blogging in the promotion of more interactive forms of science communication.
\end{abstract}

\section{Context}

\section{Science and the Public}

The latest wave in the social studies of science conceptualizes the relationship between science and the public in terms of the extension of the notion of expertise to non-scientific actors. ${ }^{10}$ This conceptualization, which considers non-scientific actors as being able to contribute to debates about science, challenges the canonical view of the public as a rather receiving agent that needs to be informed and educated. ${ }^{6,19,26}$ A shift from public understanding to public engagement with science has been characterized as citizen-oriented science or a more open, egalitarian, and participatory science. ${ }^{14,15,17,23}$ These descriptions aim to acknowledge the importance of citizens' concerns and perspectives and consider the dialog between scientific and citizen groups to be a crucial element of the modern ways of knowledge production and governance.

A range of new ways of engaging the public in dialog and decision making have been introduced in practice and discussed in scholarly literature, for example, citizen advisory committees, citizen panels and juries, and Dutch study groups. ${ }^{17,21}$ These initiatives create spaces for science and the public to meet and engage in the collective construction of knowledge claims. ${ }^{8}$ In a broader sense the spaces for public engagement with science include individual scientific creativity, ethnoscience, localized knowledge, the market, and public discourse. ${ }^{20}$ The latter, the space of public discourse, is identified by Nowotny as a hybrid space that focuses on moral, political, and cultural aspects of knowledge claims and can potentially lead to the creation of new knowledge.

The studies of public discourse as a space where knowledge claims can be sustained, contested, or redefined have addressed the issues of authority, legitimacy, framing, and agency in a variety of contexts. ${ }^{9,11,12,22,27}$ A significant amount of work focused on particular cases of scientific debates and on the role of traditional mass media in these debates. Less attention has been paid to the examination of newer forms of communication. The Internet has already become a part of science communications, and yet there is no clear and systematic understanding of how such media as forums, blogs, wikis, and so on contribute to the debates about science. 


\section{Science Blogs}

Blog is a frequently updated webpage that facilitates informal communication between the author of the blog and its audience. The blogosphere consists of multiple forms of expression that range from intimate confessions aimed at a few people to journalistic and scholarly writings that attract large numbers of readers. Depending on the style, format, and content, blogs can be characterized as personal, political, or travel blogs as well as video, spam blogs, and so on. Science blogs have been described rather loosely as blogs that focus on science or are written by scientists and science journalists. ${ }^{3}$

Science blogging is viewed as having a potential to become a new model for science journalism ${ }^{4}$ and as a powerful tool that can be used by academic institutions to disseminate scientific information and facilitate conversations about science. ${ }^{2}$ Some scientists argue though that science blogs reinforce the deficit model of science communication and blend discussions of science with ideologically driven commentary. ${ }^{5}$

So far the discussion about science blogs develops primarily in the form of journalistic and scholarly commentary rather than research-based analysis. It focuses on what blogs can and cannot do and why blogging can be a promising tool for scientists. ${ }^{7}$ Most often the analysis relies on a few examples of science blogging and uses these examples to contextualize general considerations and descriptions. ${ }^{25}$ To better understand challenges and opportunities science blogs can bring, it is necessary to analyze current practices of science blogging. To date no attempts have been made to do that. The present study is the first step in this direction.

\section{Objectives and methodology}

The ultimate goal of this study is to initiate a scholarly evidence-based discussion about the role of science blogs in promoting public engagement with science. Public engagement is conceptualized as involvement of non-scientists, i.e., individuals who are not associated with any scientific discipline or area of inquiry as part of their professional activities. Non-scientists can be involved in science in multiple ways, e.g., by engaging in discussions, participating in data collection, experimenting, providing feedback based on their knowledge of local contexts and situations, contributing to policy-making, and so on. For the purposes of this study the understanding of public engagement is limited to the engagement in meaningful conversation and dialog about scientific issues.

It is hypothesized that to facilitate public involvement in the discussions about science, science bloggers need to engage in the following activities (called modes of participation henceforth): 1) inform their readers about scientific news, 2) explain complicated matters in a manner understandable by a lay person, 3) evaluate research findings and claims made by others, 4) articulate their position toward controversial issues. Signs of public engagement with science include at least the following: a) both scientists and non-scientists are involved in blogging, b) the majority of content in posts and commentary is concerned with science and scientific issues, c) both blog authors and readers are engaged in the activities mentioned above. Given the novelty and exploratory character of this research, the examination of science blogs focuses on participants, blog sources and topical content, and modes of participation.

The data for this study consist of posts and comments from eleven blogs that write about science and technology. The blogs were sampled via the Internet search for "science blogs" and "blogs about science" and by following scientific news on the moment of data collection in Summer, 2008. Below is the list of blogs from which the posts and comments were sampled along with the blogs' URLs and authorship information (see table 1).

Before sampling blogs were examined for posting activity. As it was determined that some blogs posted one or two messages per week and others posted several messages per day, it was decided to save 30 days of activity from less active blogs and five days of activity from very active blogs. For all the blogs except BioEthics the collected posts and comments were published in July 2008. As BioEthics had insufficient activity in July 2008, the April 2008 posts and comments were collected from this blog. For the feasibility of qualitative analysis, the number of sampled comments was limited to the first 15 comments per post. Overall, 174 posts and 1409 comments from 11 blogs were saved and analyzed. 


\begin{tabular}{|cllcc|}
\hline $\mathbf{N}$ & \multicolumn{1}{|c}{ Title } & \multicolumn{1}{c}{ URL } & $\begin{array}{c}\text { Number of } \\
\text { authors }\end{array}$ & $\begin{array}{c}\text { Real } \\
\text { name } \\
\text { provided }\end{array}$ \\
\hline $\mathbf{1}$ & Pure Pedantry & scienceblogs.com/purepedantry & one & yes \\
$\mathbf{2}$ & Synthesis & www.synthesis.cc & one & yes \\
$\mathbf{3}$ & MicrobiologyBytes & www.microbiologybytes.com/blog & one & yes \\
$\mathbf{4}$ & Wired Science & www.wired.com/wiredscienc & three or more & yes \\
$\mathbf{5}$ & BioEthics & blog.bioethics.net & three or more & yes \\
$\mathbf{6}$ & DrugMonkey & scienceblogs.com/drugmonkey & two & no \\
$\mathbf{7}$ & Scientific Activist & scienceblogs.com/scientificactivist & one & ones \\
$\mathbf{8}$ & Pharyngula & scienceblogs.com/pharyngula & three or more & yes \\
$\mathbf{9}$ & Panda's Thumb & www.pandasthumb.org & three or more & no \\
$\mathbf{1 0}$ & ScienceBlog & scienceblog.com & three or more & yes \\
$\mathbf{1 1}$ & Cosmic Variance & blogs.discovermagazine.com/cosmicvariance & thes \\
\hline
\end{tabular}

Table 1. Blogs - sources of data.

A combination of quantitative and qualitative techniques of content analysis has been used in this study. The qualitative analysis involved iterative close reading of posts and comments with the purpose of identifying common types of statements and activities conceptualized as modes of participation. This conceptualization was informed by the speech act theory and the pragmatics perspective, ${ }^{1,18,24}$ yet it was purposefully left rather loose and open to allow for the categories to emerge from the data. Each time a mode of participation was identified, it was entered into a catalog, and then a post or a comment was assigned a corresponding code. Along with the modes of participation, the posts were coded for topics and sources of the post; the comments were coded for the reader's identification elements (e.g., a nickname, first name, full name, link to blog, or blog author). Subsequently all codes were counted and the analysis proceeded with the examination of the most frequent and rare patterns and their groupings.

\section{Findings}

The findings suggest that science blogs are too heterogeneous to be understood as an emerging genre of science communication. The blogs employ a variety of writing and authoring models, and no signs of emerging or stabilizing genre conventions could be observed. Even though all blogs mentioned science or a particular scientific discipline in their descriptions, they differed in their voice representations, points of view, and content orientation. Some bloggers emphasized the first person perspective and presented themselves through religious and political affiliation (e.g., "The blog is about whatever we find interesting" at Cosmic Variance or "Evolution, development, and random biological ejaculations from a godless liberal" at Pharyngula). Others shifted the focus from their personalities to the content and featured more neutral forms of presentation (e.g., "... the latest news about microbiology" at MycrobiologyBytes or "... your source for news and commentary on science" at The Scientific Activist). Differences in sources, topics, and modes of participation among blogs are discussed below.

\section{Sources}

In search for inspiration and topics, the authors relied on their personal experience, news and commentary from other media including other blogs, and research papers. Each of these categories comprised about $15 \%$ of all sources. Among other sources of blogs posts were posts from digg.com and similar aggregation websites, user comments, face-to-face communication, and TV and video sources.

Personal experience and news from other media were used to discuss predominantly non-scientific, often political, matters. ${ }^{28}$ Thus, the blog authors commented on the issues of sports doping (Pure Pedantry), children medical care and religion (BioEthics), creationism versus evolution disputes (Panda's Thumb), US presidential elections (The Scientific Activist), and the life of a Serbian politician Radovan Karadzic (Cosmic Variance).Other examples of using experienced events as sources of blog posts included reporting about conferences and public lectures, commemorating events from the past, or noticing the appearance of new material on the web. 
Sometimes personal experiences and news were also used to bring up scientific issues. Thus, in the case of sports doping (Pure Pedantry) the author also provided the information about the doping drug and its effects. In a post about experiencing an earthquake (Cosmic Variance), the author supplemented the account of his personal experience with links to the US Geological Survey website and its information about world's earthquakes. More often though, scientific matters were brought up when the authors reviewed, summarized, or simply pointed to research papers. For example, a post about magnetic bacteria at MicrobiologyBytes that described these bacteria and potential applications that can arise from the knowledge about them referred to papers published in the Annual Review of Biochemistry and Trends of Biotechnology.

\section{Topics}

The topical content of the examined science blogs is presented as a keyword cloud in the figure below. The font size corresponds to the frequency with which a particular topic appeared in blogs (i.e., the larger the font is, the more often the topic was covered in the sample).



Figure 1. Topics covered in the examined science blogs.

As can be seen from the figure above, science blogs cover a variety of issues and topics beyond science. Among the topics related to science the most frequently covered topics were evolution, health, and space. The prominence of the topics of evolution and creationism can be explained by the dominance of two highly prolific blogs Pharyngula and Panda's Thumb, which consider the promotion of evolutionary theory as their main focus. Among other scientific topics bloggers discussed genetics, physics, and biotechnology. More often, though, science bloggers discussed what has been posted on other blogs and websites and reflected on the practices in academia, on their and others' blogging, and on the issues of their personal life.

\section{Modes of participation}

The catalog of participation modes identified during the analysis of blog posts and comments consists of 50 entries. Each entry describes a particular kind of discursive activity, such as agreeing or disagreeing, advancing an argument or a position, offering an assumption, doubting, warning, and so on. All modes of participation can be grouped into at least four larger groups: contribution to the topic (e.g., report, 
argument, explanation, or clarification question), deviation from the topic (e.g., digression, insult, or selfpromotion), expression of attitudes and emotions (e.g., approval / disapproval, gratitude, regret, or sharing personal experience), and attempts to influence the actions of others (e.g., advice, recommendation, request, or proposal).

Each larger group of participation modes was equally noticeable in the sample, therefore it is difficult to claim that one form of communication or the other is more common for science blogs. Being a more fluid and personal genre of communication, blogs allow for greater variability of expression, and it seems that the authors of science blogs eagerly utilize this fluidity and variability. It was observed though, that certain blogs favored one mode of participation over the others.

\section{Authors}

The authors of the examined science blogs are all somehow related to science, yet the nature of the relationship is quite diverse. Some authors are graduate students specializing in certain areas, such as neuroscience or biochemistry, others are lecturers, researchers, and professors from certain disciplines, such as physics or biology, and others are science writers and journalists. The blog BioEthics is written by the editors of The American Journal of Bioethics, and these editors have background in medicine, philosophy, sociology, and bioethics.

To a certain extent, the diversity of authors' background explains the diversity of modes of participation. Each blog in the sample relied heavily on one or two modes of communication with other modes being rare and sporadic. For example, reporting was almost an exclusive form of communication for Wired Science blog. BioEthics blog combined reporting, explanations, and position statements. Panda's Thumb blog offered explanations and critique, but opinions and evaluations were much more common for this blog.

The reporting mode is defined in this study as an account of events or a short description of an external document. It is one of the primary modes intended to inform and communicate news. As can be seen from the excerpt below, reports tend to avoid personal opinions and judgments and present the author as a "transparent" messenger who observes and communicates reality.

\section{Excerpt 1 - Wired Science}

Out in the Mojave desert, Virgin Galactic has unveiled the new transport ship they'll be using to carry their SpaceShipTwo into suborbital space. With a 140-foot wingspan, it's the largest allcarbon composite aircraft ever built. Virgin founder Richard Branson christened the plane, EVE, after his mother. Stay tuned for more details and pictures...

Another characteristic of reporting is the use of exaggerations and generalizations. As can be seen from the excerpt below, blog authors use this journalistic technique to catch readers' attention and make the subject even more sensational.

\section{Excerpt 2 - Wired Science}

For the last 55 million years, the pen-tailed shrew has survived on a diet consisting of beer.

How's that for an evolutionary bender? The shrew lives in the forest of Malaysia and feeds on the flowers of the bertam palm. Produced year-round and constantly fermenting, its nectar is about 3.8 percent alcohol — roughly equivalent to a Sam Adams light.

The writer of this post freely interpreted the findings of the study and substituted alcohol-containing nectar mentioned in the original research with beer. This way the news becomes more entertaining, yet it may prevent the readers from getting accurate information and forming their own opinion, thereby making it difficult to rely on this form of reporting as a source of accurate information.

The explanation mode, defined in this study as making something plain or understandable, is another participation mode that can initiate the discussion and stimulate further engagement with a topic. The intention to make something understandable does not necessarily mean that it is in fact understandable. In the excerpt below, for example, the author explains the concept of antimatter and avoids technical terminology and scientific jargon. Nevertheless, it requires some knowledge of physics to understand what the author is talking about. 


\section{Excerpt 3 - Cosmic Variance}

Antimatter is just like ordinary matter in every way, except that every quantity you can think of (apart from mass and spin), is reversed. As an example, the electron is a particle with a specific mass and carrying a specific amount of negative electric charge. The antiparticle of the electron is a positron, which has the identical mass to an electron, but precisely the opposite charge. The thing about particles and their antiparticles is that, if one puts them together, the net value of any quantity (called a quantum number by physicists) carried by the pair of them is zero. Therefore, a particle and an antiparticle together are merely mass which, thanks to Einstein's E $=\mathrm{mc}^{2}$, can be converted entirely into energy. As a result of this, when matter and antimatter come together, they annihilate, producing energy in the form of light (photons).

The evaluation mode is defined as describing elements of a post in positive or negative terms such as good, bad, interesting, etc. By evaluating events, people, or documents authors and readers of science blogs can offer their opinions without spending too much time examining pros and cons or justifying their positions. Contrary to critique and argument, evaluations are a rather light form of judgment that can serve as a recommendation, an invitation to contribute, or an indication of group affiliation. Even though evaluations initiate topics, they can often be seen as deviations from topics because the intention behind evaluations is not only to discuss something, but to express and elicit certain attitudes and feelings.

In the excerpt below evaluations serve as a technique for reinforcing the boundary between two opposing groups of actors: "us," the pro-evolution authors of the blog and those readers who agree with them, and "them," the members of the creationist movement (emphasis added).

\section{Excerpt 4 - Panda's Thumb}

It is another mark of the incompetence of the ID movement that they actually hand out an award named after Casey Luskin. Pick the most ineffectual, uninformed, pathetic loser on the creationist side, and use his name to inspire the next generation of IDiots. It's actually amusingly appropriate.

Emotional and often insulting evaluations are very common for this and some other blogs that seem to be eager to demonstrate not only their rightness, but also to distinguish their group of reasonable and worthy individuals from others, who are wrong, unintelligent, and overall worthless. The frequency of such evaluations and mockery undermines the goals of rational debate and criticism. Such activities can foster solidarity among the like-minded individuals, yet at the same time, they may spur hostility in those who are undecided or hold a different opinion.

Less complicated common forms of author participation in science blogs included announcements and summaries of documents. Announcements publicize events and sources of information (e.g., "The Kaiser network is hosting a live webcast to discuss the influence of the blogosphere on health policy" or "Tonight, on the History Channel... It's the much anticipate first episode of a new series, Evolve Eyes"). Summaries provide elaborate descriptions of research papers and essays and often use very specific terminology such as dorsolateral prefrontal cortex, which would require the reader to have some background in a particular field. While such summaries somewhat popularize the content of research papers, the amount of minimal background necessary for a lay person to understand and follow the research news varied among different science blogs.

\section{Readers}

Readers of science blogs also had some relationship with science, i.e., they were not exactly non-scientists or lay persons. One author posted a message titled "Who are you?" and asked his readers for information about themselves and their background. The answers to this post as well as the overall analysis of readers' comments demonstrate that those readers who engage in commenting are almost always associated with science one way or another. They are graduate students, postdoctoral associates, faculty members, and researchers from a variety of scientific and research fields including biology, physics, neuroscience, and medicine. Wired Science was probably the only blog in the sample where non-scientists formed a considerable portion of the commenting audience. Nevertheless, even in this blog commenters often took the position of authority and talked as experts who are quite knowledgeable about the subject. 
The interest in particular blogs for such expert and scientist readers is determined by their needs to get news on a broader set of scientific topics, to learn about the developments in other scientific fields, or to engage in conversations with like-minded colleagues and science bloggers. As one reader noticed, science blogs are virtual water coolers, where fellow scientists and researchers can virtually get together and talk about "what's interesting in research topics, what's up with funding, looking for trends and needs."

The water cooler metaphor also fits with the light-weight nature of comments. While some readers contributed to the development of topic by building upon a post and previous comments and adding something to it, e.g., a new thought, an idea, a non-clarifying question, or an answer to a non-clarifying question, a large portion of comments was concerned with short expressions of personal attitudes or digressed from the topic discussed in the blog post. Below is an example of how the first comment to the post about Louisiana creationism law and its criticism by the conservative writer John Derbyshire generated the whole discussion about Barack Obama and his presidency in response:

\section{Excerpt 5 - Panda's Thumb}

Derbeyshire is either confused, or very disingenuous, in labeling Jindal a dupe. Jindal knows exactly what this bill is all about, knows what the DI does for a living, and is making a carefully calculated appeal to what he gambles will be a large enough voting bloc in Louisiana and perhaps the US, to ride much further. I imagine he's reading the handwriting on the same wall Obama is reading from (in publicly supporting "faith-based initiatives"). These guys are pros, with outstanding political sensitivities. Apparently, you can't win without the bible bangers.

After this comment a thread of comments developed defending or criticizing Barack Obama and his approach to science, religion, politics, and so on. These comments were completely unrelated to the topic of Louisiana creationism law provided by the blog post. ${ }^{29}$

Comments concerned with expressing personal feelings and attitudes consisted of sharing personal experiences, insulting other participants, thanking, and stating one's position about a controversial issue. Sharing personal experiences was often triggered by discussions of events or situations that somehow affected readers personally (e.g., "I'm about 20 miles from the epicenter. A lot of shaking and noise, but shouldn't be any major damage" or "My daughter suffered horribly from ear infections until 3rd grade"). Sharing personal details was also used as a form of establishing authority. For example, in the discussion about the dangers of nuclear weapons one commenter backed up his opinion that mutually assured destruction (MAD) is a viable defense against nuclear attack with the information that as a naval officer he had served on two different ballistic missile submarines.

Insults, such as "Don't be an idiot.. rtfa" or "Could you possibly sound any more stupid with this comment?" were more common for some blogs than the others. Thus, Wired Science and Panda's Thumb were filled with insulting commentary. Offensive remarks regarding somebody's personality or intellectual abilities most often targeted other commenters and the characters of posts, but sometimes they were directed at blog authors as well, such as the following comment in DrugMonkey blog: "You are correct, I never read a post in which you claim not to be pompous and arrogant".

In addition to personal attitudes and obvious digressions, where commenters would take an element from a blog post and develop it into an independent topic of conversation, a large portion of comments offered humorous and sarcastic remarks. Thus, the Wired Science post about nuclear weapons as a way to destroy asteroids got the following comments among others: "Got Bruce Willis?", "You don't want to destroy or deflect comets or asteroids, you want to capture and harvest them...", and "Like the SF writers of yore knew: Resistance is Futile".

Sarcasm was often used as a way to offer disagreement or disapproval or question the credibility of the message, its author, or its source. In the excerpt below, for example, the reader makes a sarcastic remark to criticize the existing capitalism system in relation to the development and distribution of drugs:

\section{Excerpt 6 - Wired Science}

But would big pharma really be needed to produce massive amounts? There are already companies that do just fine selling generics. And perhaps a whole new industry will emerge to meet the demand for drugs like Rember, which would be great.

After all, unlike drugs which meet the needs of millions of poor people, Rember would meet the needs of millions of relatively rich people. Go capitalism! 


\section{Discussion}

Science blogs examined in this study are very heterogeneous. They provide information and explain complicated matters, but their evaluations are often trivial and they rarely provide extensive critique or articulate positions on controversial issues. Kenix ${ }^{16}$ analyzed political news blogs as alternative news sources and found that the blogs offered binary, reductive analysis and dependent reporting. She also found that readers often provided caustic commentary and argued that comments can be considered a separate communicative sphere more akin to a neighborhood bar than to the Habermasian public sphere. It appears that science blogging can also be characterized as relying on reductive analysis and dependent reporting and drawing caustic and petty commentary. These characteristics may as well be applied to the newspaper and magazine science communication, but with the newer science communication outlet such as blogging they indicate that the potential of blogging to do something differently, e.g., to provide informed expert and citizen commentary, is not realized.

In their current multiplicity of forms and contents science blogs present a challenge rather than an opportunity for public engagement with science. Lack of genre conventions, which for the audience translates into broken expectations and uncertainty, impedes the development of stable readership and participation from the larger public, which may also be very heterogeneous. The "neighborhood bar" or "water cooler" commentary creates a sense of community with shared context and culture, but at the same time it creates a barrier that prevents strangers and outsiders from joining the conversation. As a community of scientists or individuals close to science, the existing readers may enjoy the entertaining nature of science blogs and not need science blogs to serve as a place for discussion and rational debate. Relying on such community of readers, bloggers may reduce their interpretive activities and resort to copying, re-distributing, and re-packaging of the existing information, which is still quite rewarding given the background of the majority of current readers and yet requires much less time and effort.

This study provides further evidence that blogging as a web tool has no magic properties on its own. Without a concerted effort of different social actors involved it will not solve any problems. Certain developments, such as public engagement with science, can only be facilitated if the technology is embedded within the network of social actors and structures. With regard to science blogging, it would perhaps require a joint effort of scientists, journalists, educators, and other groups of actors to re-think the role of blogging in the promotion of participatory science. As one paper noted in relation to the issue of participant involvement in digital libraries, participation requires human moderation, technological mediation, and a significant investment of time, effort, and money. ${ }^{13}$

This study has a number of limitations. The study is based on a limited sample, and the applicability of its findings and conclusions needs to be tested further. The findings can serve as an initial step in the investigations of the relationship between science blogging and public engagement with science and in the development of the taxonomy of modes of participation. Due to the small number of posts and comments, certain important modes of participation could have been overlooked. A more elaborate taxonomy of participation modes could serve as a basis for further genre analysis of science blogging. The role of humor in science communication and collective interpretation of knowledge also needs to be examined. Finally, the study would benefit from extending the analysis to lurkers, i.e., those readers who follow the content but do not post comments.

\section{Conclusion}

This study examined posts and comments from eleven science blogs in an attempt to answer the question of whether they can facilitate public engagement with science. The findings suggest that the majority of individuals involved in science blogging as both authors and readers are professional scientists or future professional scientists. Science blogs are a virtual water cooler for graduate students, postdoctoral associates, faculty, and researchers from a variety of disciplines and areas of inquiry.

The conversations in science blogs are also of "water cooler" quality. Bloggers alternate explanations and critical commentary with quick personal opinions, re-posting of content from news sources and other blogs, and humorous and sarcastic remarks. Readers respond with similar actions and in addition to topic developments offer quick personal judgments, insulting and sarcastic remarks, and personal details. To become a tool for non-scientist participation, science blogs need to stabilize as a genre or as a set of subgenres where smaller conversations may facilitate more meaningful participation from members of 
the public. ${ }^{30}$ Science bloggers need to become more aware of their audience, welcome non-scientists, and focus on explanatory, interpretative, and critical modes of communication rather than on reporting and opinionating. An interesting practical experiment would also be to reverse the roles of writers and readers and invite the so called "ordinary persons" to create and publish science blogs, i.e., to engage them in the practices of science blog writing rather than reading or commenting.

\section{Notes and references}

J.L. Austin (1975), How to do things with words, Cambridge, MA: Harvard University Press.

2 S.A. Batts, N.J. Anthis and T.C. Smith (2008), Advancing science through conversations: Bridging the gap between blogs and the academy, PLoS Biology, 6(9), 1837.

L. Bonetta (2007), Scientists enter the blogosphere, Cell 129(3): 443-445.

G. Brumfiel (2009), Science journalism: Supplanting the old media?, Nature 458: 274-277.

T. Bubela et al. (2009), Science communication reconsidered, Nature Biotechnology 27(6), 514-518.

M. Bucchi (1998), Science and the media: Alternative routes in scientific communication, New York: Routledge.

7 D. Butler (2005), Science in the web age: Joint efforts, Nature 438(7068): 548-549.

8 M. Callon (1999), The role of lay people in the production and dissemination of scientific knowledge, Science, technology \& society 4(1), 81-94.

9 H. Calsamiglia and C.L. Ferrero (2003), Role and position of scientific voices: Reported speech in the media, Discourse Studies 5(2), 147-173.

10 H. Collins and R. Evans (2002), The third wave of science studies: Studies of expertise and experience, Social Studies of Science 32(2), 235-296.

11 G. Cook, E. Pieri and P.T. Robbins (2004), 'The scientists think and the public feels': Expert perceptions of the discourse of GM food, Discourse Society 15(4), 433-449.

12 H.T. Engelhardt and A.L. Caplan (1987), Scientific controversies: Case studies in the resolution and closure of disputes in science and technology, Cambridge; New York: Cambridge University Press.

13 S. Giersch, et al (2004), If you build it, will they come? Participant involvement in digital libraries, D-Lib Magazine 10(7/8), retrieved from http://www.dlib.org/dlib/july04/giersch/07giersch.html.

14 A. Irwin (1995), Citizen science. London; New York: Routledge.

15 S. Jasanoff (2003), Technologies of humility: Citizen participation in governing science, Minerva 41(3), 223-244.

16 L.J. Kenix (2009), Blogs as alternative, Journal of Computer-Mediated Communication 14(4): 790-822.

17 M. Leach, I. Scoones and B. Wynne (2005), Science and citizens, London: Zed Books.

18 S.C. Levinson (1983), Pragmatics, Cambridge UK, Cambridge University Press.

19 B. Lewenstein (1995), Science and the media, In S. Jasanoff, G. E. Markle, J. C. Petersen, \& T. Pinch (Eds.), Handbook of science and technology studies (pp. 343-360). Thousand Oaks, CA: Sage Publications.

20 H. Nowotny (1993), Socially distributed knowledge: Five spaces for science to meet the public, Public Understanding of Science 2(4): 307-319.

21 O. Renn, T. Webler and P.M. Wiedemann eds. (1995), Fairness and competence in citizen participation, Dordrecht, the Netherlands: Springer.

22 D. Rose and S. Blume (2003), Citizens as users of technology: An exploratory study of vaccines and vaccination, In N. Oudshoorn and T. Pinch (Eds.), How users matter: the co-construction of users and technology (pp. 103-132), Cambridge, Mass.: MIT Press.

23 M.S. Schafer (2009), From public understanding to public engagement: An empirical assessment of changes in science coverage, Science Communication 30(4): 475-505.

24 J.R. Searle (1969), Speech acts, Cambridge, UK: Cambridge University Press.

25 J.S. Wilkins (2008), The roles, reasons and restrictions of science blogs, Trends in Ecology \& Evolution 23(8): $411-413$.

26 B. Wynne (1995), Public understanding of science, in S. Jasanoff, G. E. Markle, S.F.S.S.O. Science and J.C. Petersen (Eds.), Handbook of science and technology studies (pp. 361-388), Thousand Oaks, CA: Sage Publications.

27 B. Wynne (2003), Misunderstood misunderstandings: Social identities and public uptake of science, in A. Irwin and B. Wynne (Eds.), Misunderstanding science?: The public reconstruction of science and technology (pp. 65-83). Cambridge; New York: Cambridge University Press.

28 Even though some of the topics could be considered to be a matter of science and some other domain (e.g., politics or history), a topic was considered non-scientific when no connections to scientific knowledge, methods, or processes had been made in the post. This rather restrictive assumption about the content of science blogs will hopefully generate more scholarly discussions about the purpose, genres, and practices of science blogging.

29 The low level of spam messages in the blogs indicates the use of some moderation mechanisms. However, it was not examined in this study whether the authors engage in extensive moderation of reader comments and to what extent the published comments are the result of such moderation.

30 The author is grateful to an anonymous reviewer for pointing out the usefulness of smaller conversations rather than one big public conversation. This seems to be a very fruitful idea worth further exploration. 


\section{Author}

Inna Kouper is a doctoral candidate in the School of Library and Information Science, Indiana University Bloomington. Her current research interests lie broadly in the areas of language and information; the role of science in society; and the evolution of information and communication technologies generally described as social or participatory media (such as blogs, wikis, podcasts, etc.).

E-mail: inkouper@indiana.edu.

HOW TO CITE: I. Kouper, Science blogs and public engagement with science: practices, challenges, and opportunities, Jcom $\mathbf{0 9}(01)$ (2010) A02. 